\title{
COMO UTILIZAR A PESQUISA PARA MELHOR ORIENTAR A AÇÃO DA ENFERMAGEM
}

\author{
Amália C. de Carvalho*
}

CARVALHO, A.C. de - Como utilizar a pesquisa para melhor orientar a ação da enfermagem. Rev. Esc. Enf. USP, 9 (1): 20-26, 1975.

A autora faz breves considerações sobre a importância da utilização do método científico na enfermagem, focalizando a necessidade de incrementar o emprego dessa metodologia entre nós, na resolução dos problemas que surgem em situaç̃es de ensino e na prática da profissão. Realçou a importância de serem proporcionados aos enfermeiros meios para que possam aprofundar os conhecimentos em sua área de atuação e na metodologia científica, a fim de que se tornem capazes de analisar criticamente as pesquisas de enfermagem já publicadas, utilizar esses resultados no seu campo de atividades, ou fazer as próprias investigaçc̃es à procura da solução para os problemas encontrados no exercício de suas funçðes. Citou tipos de pesquisas realizadas em aŕeas intimamente ligadas às atividades de saúde pública, cujos resultados poderão orientar a ação da enfermeira de saúde públıca.

$\mathrm{O}$ assunto a ser abordado nesta reunião deverá colaborar para que seja atingido o quarto objetivo do Seminário: Estimular o desenvolvimento da pesquisa como condição indisoensável para um trabalho efetivo e para o aumento da competência profissional A focalização do subtema, título da presente palestra, tem o propósito de orientar as enfermeiras de saúde pública sobre a utilização da pesquisa como um dos meios de conseguir melhores resultados da sua intervenção junto ao indivíduo, família e comunidade, no exercício de suas atividades profissionais.

\footnotetext{
- Trabalho apresentado no Seminário sobre Enfermagem de Sáude Pública realizado na Escola de Enfermagem da UFBA, de 5 a 10 de agosto de 1974.

- Professor Assistente Doutor da Disciplina Metodologia de Pesquisa em Enfermagem
} 
A fim de iniciar a abordagem do assunto pela apresentação de fatos, é necessário que se faça uma breve retrospectiva sobre a utilização da metodologia científica na enfermagem sob seu aspecto geral, antes de focalizá-la como instrumento indispensável ao desenvolvimento e à eficiência das medidas a serem adotadas pelas enfermeiras de saúde pública.

A utilização do método científico na enfermagem foi introduzida pela própria criadora da moderna profissão. Florence Nightingale preconizava a observação sistemática como base para a tomada de decisões com relação à assistência que os pacientes deveriam receber. Seus livros, cartas e notas enfatizavam esse aspecto e deixavam entrever uma preocupação maior com a determinação de um corpo de conhecimentos de enfermagem que guiassem as açōes dos profissionais sob sua orientação.

Pena que esse espírito profundamente inquiridor da celebrada e revolucionária pioneira não tivesse tido continuadoras nas suas auxiliares e discípulas inglesas. Durante muitas décadas a preocupação maior do grupo que a sucedeu não foi investigar, descobrir, inovar, mas apenas seguir uma trilha já traçada e provada adequada para as necessidades da época.

O despertar para a pesquisa deu-se, já neste século, com as enfermeiras norte-americanas, empenhadas na luta pela elevação dos padrões de ensino de enfermagem. As primeiras incursões no campo da investigação foram feitas meio a medo e até bem pouco tempo restringiam-se às áreas, por assim dizer, periféricas da profissão. Focalizavam os aspectos relacionados com o próprio profissional, suas características, preparo, aspirações e campos de atuação e com os aspectos administrativos da prática hospitalar ou de saúde pública. Evitavam abordar os problemas da assistência de enfermagem propriamente dita, sobre os quais muito se falava e pouco se dizia.

A ênfase atual na necessidade de se criar as bases para o desenvolvimento de uma teoria de enfermagem ou de teorias de enfermagem, fundamentadas no estudo sistemático da respectiva prática, constitui um marco na etapa do progresso da profissão.

\section{A ENFERMAGEM E A PESQUiSA NO BRASIL}


profissionais, principalmente por meio das enfermeiras que se dedicam à docência nas escolas universitárias, engajadas em programas de pós-graduação ou candidatas a concursos para cargos no magistério superior. $O$ incentivo dado pela Associação Brasileira de Enfermagem, tornando a pesquisa um dos temas oficiais dos seus congressos e premiando os melhores trabalhos de investigação, tem contribuído também para o progresso lento, mas contínuo, que vem sendo observado nesse campo.

Entretanto, o lento caminhar já não é aceitável numa era de progressos rápidos em todos os setores da vida humana; não pode ser aceito na esfera da assistència à saúde, não deve ser mantido no campo da assistência de enfermagem.

Uma análise superficial da situação mostra sérias deficiências no sistema de ensino de enfermagem no País, a começar pela existência de um círculo vicioso difícil de ser quebrado: a ênsafe no fazer, relegando o pro cesso reflexivo para o segundo plano; baseia-se no conhecimento empírico, nem sempre se preocupando com o desenvolvimento do raciocínio, do espírito de curiosidade, de dúvida, de indagação. As enfermeiras foram, e em algumas instâncias continuam sendo, preparadas para executarem tarefas, não para resolverem problemas através da utilização da metodologia científica. Formadas nesse sistema, muitas das atuais docentes ainda não conseguiram superar a falha do processo e a perpetuam em suas classes, utilizando tecnologia educacional ultrapassada e voltada ainda apenas para o desenvolvimento da eficiência técnica.

A pesquisa é uma atividade que depende da posse de certas qualidades por parte do pesquisador, qualidades essas que podem ser desenvolvidas ou aperfeiçoadas no decorrer da vida, através do esforço pessoal e de orientação dirigida. Uma delas é o espírito científico. Possuí-lo é estar preparado para tentar a resolução dos problemas que surgem no cotidiano, profissionais em sua majoria, aplicando métodos adequados; é ser curioso e saber observar os fenômenos que circundam o objeto de suas indagaçðes, é ser capaz de analisar e criticar fatos e idéias racionalmente; é ser honesto e imparcial; é julgar com sabedoria e objetividade.

Entretanto, possuir apenas espírito científico não basta. Para fazer pesquisas e ser capaz de analisar criticamente qualquer trabalho de investigação é necessário o conhecimento da metodologia científica, teórico 
e aplicado em situações criadas para esse aprendizado.

FLEMING \& HAYTER *, ao apresentarem sugestões para o desenvolvimento da capacidade de análise crítica das pesquisas de enfermagem, por parte das enfermeiras, assim se expressam: as enfermeiras têm se mostrado relutantes em fazerem análises críticas das pesquisas de outras enfermeiras... entretanto, as que deverão por em prática e avaliar as idéias apresentadas na literatura necessitam estar capacitadas para avaliar criticamente os relatórios de pesquisa, se quiserem julgar corretamente o que é e o que não é aceitável na prática. Da mesma maneira, antes que alguém possa fazer pesquisa, deverá ser capaz de julgar o trabalho de outros pesquisadores. E os mesmos autores continuam, dizendo: a análise critica exige que o leitor tenha algum conhecimento de pesquisa e do assunto do estudo em questão $e$ que possua capacidade de, ao fazer a avaliação, julgar com critério.

Estarão as enfermeiras brasileiras sendo preparadas para isso? Quando e como recebem esse preparo? Serão realmente capazes de avaliar os resultados de uma pesquisa em termos da validade do método e dos instrumentos utilizados na coleta dos dados? Do método empregado para a análise e interpretação desses dados? Da adequação da amostra escolhida? Conhecem estat ística o suficiente para avaliar da correção dos procedimentos usados e dos resultados finais?

Se estão preparadas, o que fazer para diminuir a resistência ativa ou passiva que parecem opor a qualquer idéia de experimentação e mudança? $O$ que fazer para provocar o seu envolvimento total, a ponto de se disporem a colaborar com as poucas enfermeiras que se aventuram nesse campo? ou a ponto de se disporem a avaliar os resultados das pesquisas e utilizá-los na prática da enfermagem?

É bem possível que as respostas a essas indagaçōes não sejam muito animadoras e que, entre nós, ainda seja necessário incentivar as escolas de enfermagem e suas docentes para uma mudança radical na maneira como vem sendo conduzido o ensino das disciplinas de enfermagem. A utilização ção do método científico na resolução dos problemas de enfermagem encontrados pelas estudantes, durante a prática de campo, deve constituir a estratégia básica desse ensino. A inclusão, nos currículos de graduação, de uma disciplina destinada a apresentar os aspectos metodológicos do processo, constitui uma necessidade inadiável, se é que realmente se deseja que a enfermeira 
seja capaz de utilizar a pesquisa para melhor orientar a açāo de enfermagem.

\section{ENFERMAGEM DE SAÚde PÚBlica E PESQUisa}

Como nos demais campos da enfermagem, a saúde pública apresenta-se como uma vasta área ainda inexplorada pelas enfermeiras com relação às pesquisas. Mesmo havendo poucos trabalhos especificamente de enfermagem, porém, as oportunidades de utilização dos resultados de pesquisas na prática profissional são muito variadas. $O$ interesse em resolver problemas de saúde da comunidade tem determinado um grande número de investigaçōes por parte dos outros profissionais da saúde: médicos e engenheiros sanitaristas, veterinários, biólogos, nutrólogos e outros mais. As enfermeiras podem e devem tomar conhecimento desses trabalhos, analisá-los criticamente e aproveitar as descobertas realmente válidas para aplicá-las em seu trabalho junto aos grupos populacionais a que atendem.

$\mathrm{Na}$ área relacionada com a educação para a saúde, por exemplo, esses recursos são abundantes e de muito boa qualidade. Pesquisadores, alguns de renome mundial, têm apresentado trabalhos cujos resultados, se utilizados pelas enfermeiras, poderiam enriquecer sua contribuição nos diferentes setores da educação sanitária. Dentre os variados tópicos que a literatura oferece, alguns merecem menção por estarem intimamente ligados às atividades assistenciais do pessoal de enfermagem:

tecnologia da educação para a saúde: eficiência ou falhas das estratégias utilizadas e dos recursos audiovisuais selecionados; modificaçðes tecnologicas necessárias, de acordo com as características de cada grupo populacional;

- técnicas empregadas para motivar grupos de diferente poder aquisitivo e de diferentes interesses a aceitarem a supervisão de saúde; educação para a saúde;

- problemas de comunicação e de relaçð̃es interpessoais na

- problemas alimentares de grupos populacionais, incluindo tabús, aspectos sócio-econômicos da seleção de alimentos, sua conservação e perigos de contaminação; 
transmissiveis, etc..

- resultados das pesquisas no campo da profilaxia das doenças

Sem ter esgotado as possibilidades na área da educação para a saúde, convém mencionar ainda a produção em outras áreas e que incluem trabalhos sobre: estatística vital, mortalidade de crianças e adultos e expectativa de vida; saneamento ambiental; planejamento de recursos humanos para a saúde, abordado sob o ponto de vista da formação de pessoal, do tipo e adequação das categorias às funçðes, treinamento em serviço, melhor aproveitamento dos recursos existentes; estudos demográficos e dinâmica populacional; estudos epidemiológicos; problemas de saúde dos países em desenvolvimento e outros mais.

As oportunidades para as enfermeiras fazerem pesquisas no campo da enfermagem de saúde pública existem, assim como a possibilidade de se utilizarem dos resultados das investigaçðes científicas dos demais profissionais da equipe de saúde em suas atividades assistenciais.

As enfermeiras sabem que precisam fazer pesquisas; que os problemas de enfermagem devem ser estudados e resolvidos por meio da utilização da metodologia científica; que há necessidade de produzir mudanças nas técnicas de abordagem desses problemas, a fim de que a população a ser assistida o seja adequadamente; que há necessidade de incentivar a experimentação de novos métodos, técnicas e estratégias de ensino, ou de novos procedimentos na prestação da assistência de enfermagem.

Saberão fazê-lo? Estarão sendo preparadas para isso? Pior, talvez, que não fazer pesquisas será improvisá-las; será imaginar que se descobriu algo de novo e que poderá ser um resultado falso, completamente errado, inaceitável na prática.

É muito importante e necessário, portanto, incentivar as profissionais a fazerem pesquisas na sua área de atuação; a lerem e analisarem criticamente as pesquisas feitas por colegas; a aplicarem os resultados das investigaçðes científicas em suas atividades junto aos grupos populacionais a que asistem; a desenvolverem atitude positiva em relação aos trabalhos de investigação.

Não menos importante e necessário, porém, será dar às enfer- 
meiras as condiçōes para levarem a cabo mais essa tarefa: propiciar-lhes os meios para que possam aprofundar os conhecimentos em sua própria área de atuação e na enfermagem em geral; facilitar o desenvolvimento de conhecimento sobre a metodologia científica e de habilidade na sua utilização; prover orientação e ajuda, quando isso for solicitado; garantir disponibilidade de tempo e de condições para o trabalho de pesquisa.

Vencida essa primeira etapa, de preparar as enfermeiras brasileiras para atuarem no campo da pesquisa, a segunda etapa, relativa à utilização dos resultados da investigação científica para melhor orientar a ação da enfermagem, será sua consequeência lógica. Sabendo fazer ou analisar pesquisas, as enfermeiras estarão aptas a aplicar os resultados em suas atividades profissionais.

Este ponto de vista é discutível e poderá ser refutado pelos membros deste seminário. Oxalá os grupos discordem da autora e apresentem fatos que venham enriquecer seus conhecimentos sobre o assunto.

CARVALHO, A.C. de - Utilization of research in nursing. Rev. Esc. Enf. Enf. USP, 9 (1): 20-26, 1975.

The author showed the importance of the utilization of scientific methodology in nursing, giving emphasis on the need of employing it in the solution of nursing problems met both in nursing education and nursing practice. She stressed the need of offering the nurses opportunities to improve the knowledge in their own specialties and in the research methodology. 